Bull. Mater. Sci., Vol. 8, No. 4, October 1986, pp. 479-488.

(C) Printed in India.

\title{
Determination of oxygen to metal ratio of U-Pu mixed oxides by $x$-ray diffraction
}

\author{
RAVI VERMA and P R ROY \\ Radiometallurgy Division, Bhabha Atomic Research Centre, Bombay 400 085, India \\ MS received 13 March 1986
}

\begin{abstract}
The possibility of measuring the oxygen-metal ratio $(\mathrm{O} / \mathrm{M})$ of U-Pu mixed oxides by $\mathrm{x}$-ray diffraction technique has been explored. In single-phase U-Pu mixed oxides, the lattice parameter vs $\mathrm{O} / \mathrm{M}$ plots for different plutonium concentrations are drawn by interpolation of lattice parameter values between those of $\mathrm{UO}_{2}, \mathrm{PuO}_{2}$ and $\mathrm{Pu}_{2} \mathrm{O}_{3}$. These plots are then used for determining the $\mathrm{O} / \mathrm{Ms}$ of unknown samples against their experimentally measured lattice parameter values. In two-phase mixed oxides, the mole fractions of the two phases are determined from the intensities of their selected diffraction lines. The $\mathrm{O} / \mathrm{M}$ of the mixed oxide is then given by the mole average of the individual $\mathrm{O} / \mathrm{Ms}$ of the two phases.
\end{abstract}

Keywords. Oxygen-metal ratio; uranium plutonium oxides; $x$-ray diffraction.

\section{Introduction}

The oxygen-to-metal ratio $(\mathrm{O} / \mathrm{M})$ is an important parameter governing many properties of the U-Pu mixed oxide fuels. It is well known that deviation from stoichiometry assists in the sintering of mixed oxide compacts (Belle 1961; Lay 1971). The $\mathrm{O} / \mathrm{M}$ also affects fuel properties such as thermal conductivity (Zebroski et al 1965; Gibby 1969) and melting point (Lyon and Baily 1965). Diffusion coefficients and vapour pressures have also been reported to change by 3 or more orders of magnitude for a minor change of 0.02 in the $\mathrm{O} / \mathrm{M}$ near the value of 2.00 (Matzke 1976). A knowledge of $\mathrm{O} / \mathrm{M}$ of the mixed oxide fuel, therefore, is very essential.

$A$ variety of $\mathrm{O} / \mathrm{M}$ measurement techniques have been developed and used over the past several years with varying degree of success. Lyon (1963) reviewed several of these techniques and recommended a thermogravimetry method of $\mathrm{O} / \mathrm{M}$ measurement. McNeilly and Chikalla (1971) improved upon the two-step method and suggested a single heat treatment of the sample at $1073 \mathrm{~K}$ for $6 \mathrm{hr}$ in an atmosphere of $\mathrm{Ar}-8 \% \quad \mathrm{H}_{2}$ passed over a water trap maintained at $273 \mathrm{~K}$. The method has an accuracy of \pm 0.002 . The thermogravimetry method requires an accurate balance, a furnace and a gas handling system which make it difficult to adopt it as an on-line method of $\mathrm{O} / \mathrm{M}$ measurement in a commercial fuel production plant. Lattice parameter measurement can be conveniently used to measure $O / M$ in single-phase mixed oxides. In this paper, different methods of $\mathrm{O} / \mathrm{M}$ measurement based on $\mathrm{x}$-ray diffraction analysis are presented for single-phase and for two-phase mixed oxides. The results of $\mathrm{O} / \mathrm{M}$ measurements obtained using these methods are discussed.

\section{U-Pu-O system}

Before discussing the $\mathrm{x}$-ray methods, it is worthwhile to examine some phase relationships in the ternary U-Pu-O system. Since the recommended fuel for liquid 
metal fast breeder reactors is a hypostoichiometric mixed oxide, the discussion would be restricted only to this region of the ternary phase diagram.

The phase diagram in figure 1 (Markin and Street 1967) shows that for plutonium concentrations less than $30-35 \%$, the hypostoichiometric mixed oxide exists as a single fcc phase. The remarkable ability of the mixed oxide to lose oxygen without undergoing a phase transformation is attributed to the conversion of $\mathrm{Pu}^{4+}$ ions to $\mathrm{Pu}^{3+}$ ions. The $\mathrm{O} / \mathrm{M}$ limit of the single phase region corresponds to a state in which all the plutonium in the mixed oxide is reduced to $\mathrm{Pu}^{3+}$. Uranium, on the other hand, remains tetravalent throughout the reduction of the mixed oxide. For plutonium concentrations more than $30-35 \%$, the hypostoichiometric mixed oxide exists as a mixture of two phases-the stoichiometric $\mathrm{MO}_{2.00}$ phase and a substoichiometric $\mathrm{MO}_{2-x}$ phase. The $\mathrm{O} / \mathrm{M}$ of the latter phase corresponds to all the plutonium in $\mathrm{Pu}^{3+}$ state. The phases, $\mathrm{MO}_{2.00}$ and $\mathrm{MO}_{2-x}$, have the fcc structure upto a plutonium concentration of $50 \%$ (Brett and Russell 1963), beyond which the $\mathrm{MO}_{2-x}$ phase shows a bcc structure (Brett and Russell 1963; Dean 1965). Further, it has been shown (Dean et al 1970) that the hypostoichiometric mixed oxide containing $76 \%$ plutonium shows a rhombohedral phase in equilibrium with the fcc $\mathrm{MO}_{2.00}$ phase. The $\mathrm{O} / \mathrm{M}$ of the rhombohedral phase is reported to be 1.70 , which means that only a part of plutonium in this phase exists in $\mathrm{Pu}^{3+}$ state.

\section{Methods}

\subsection{Single-phase mixed oxide}

The $\mathrm{x}$-ray diffraction method for determining $\mathrm{O} / \mathrm{M}$ in a single-phase mixed oxide is based on finding a correlation between the lattice parameter and the $O / M$ of the

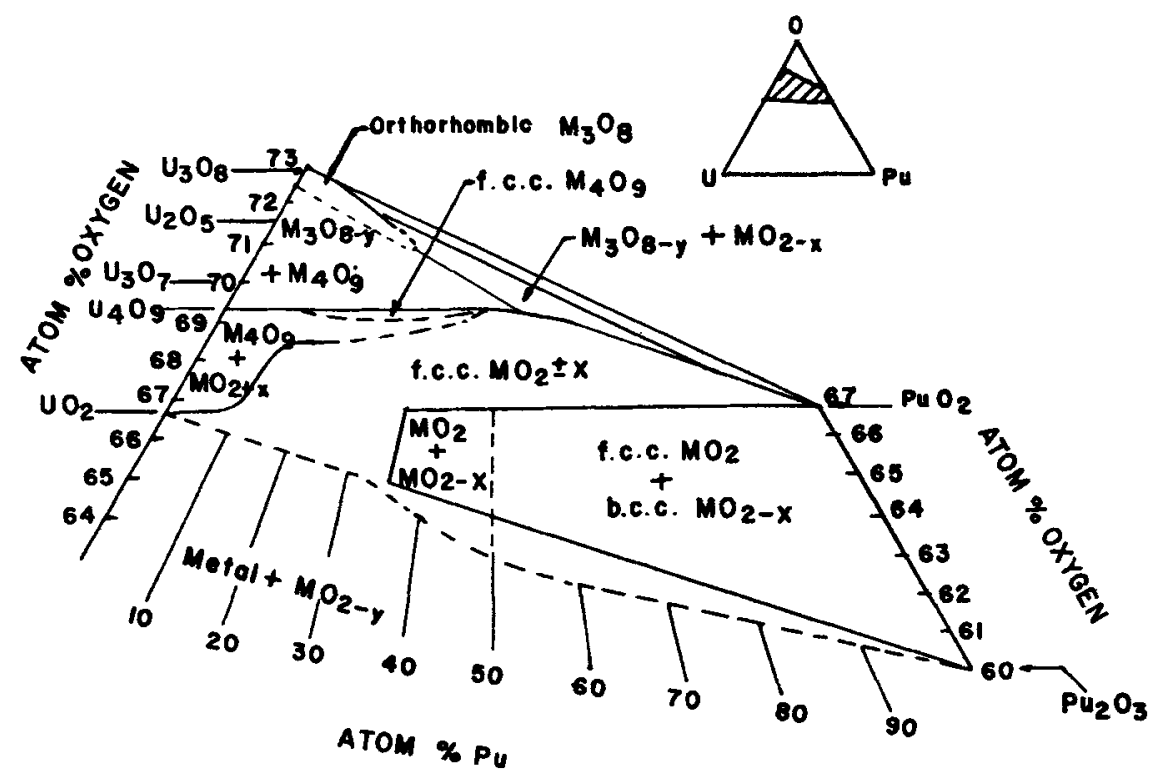

Figure 1. A section of $\mathrm{U}-\mathrm{Pu}-\mathrm{O}$ ternary equilibrium diagram. 
mixed oxide. Lattice parameter values determined by the x-ray diffraction technique are plotted against $\mathrm{O} / \mathrm{M}$ values measured by the thermogravimetric method for different plutonium concentrations of the mixed oxide (Dean and Pascard 1967; Blank et al 1967; Markin and Street 1967). These plots are then used to obtain the $\mathrm{O} / \mathrm{M}$ values for unknown samples.

The lattice parameter vs $\mathrm{O} / \mathrm{M}$ plots for different plutonium concentrations can also be drawn on the basis of the following consideration.

The lattice parameter of a stoichiometric mixed oxide varies linearly with plutonium content from $\mathrm{UO}_{2}$ to $\mathrm{PuO}_{2}$ (Mufford and Ellingor 1958). Dean et al (1970) showed that the lattice parameter of a fully reduced mixed oxide (i.e. all plutonium in $\mathrm{Pu}^{3+}$ state) varies linearly with plutonium content, from $\mathrm{UO}_{2}$ to $\mathrm{Pu}_{2} \mathrm{O}_{3}$. Further, there is ample evidence (Dean and Pascard 1967; Blank et al 1967; Markin and Street 1967) indicating that the lattice parameter of a mixed oxide of given plutonium concentration varies linearly with its oxygen content. These observations suggest that, in general, the lattice parameter of a hypostoichiometric mixed oxide can be obtained by linear interpolation between the lattice parameter values of $\mathrm{UO}_{2}, \mathrm{PuO}_{2}$ and $\mathrm{Pu}_{2} \mathrm{O}_{3}$. Details of the interpolation are shown in figure 2. Dean's lattice parameter vs plutonium content plot for fully reduced mixed oxide (line $a$ in the

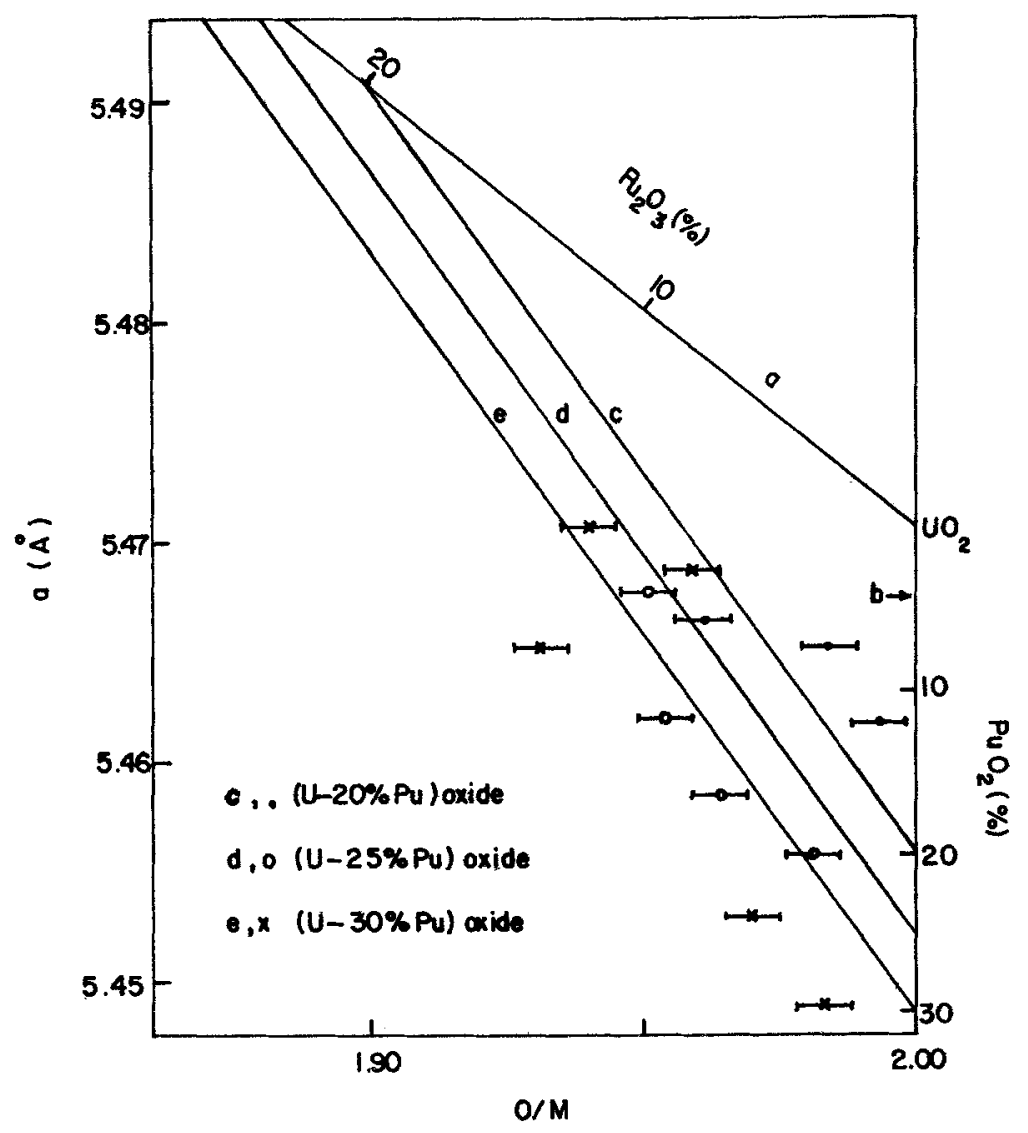

Figure 2. Dependence of lattice parameter on $\mathrm{O} / \mathrm{M}$ for different compositions of the single phase mixed oxide; theoretical plots (-) and the experimental data points. 
figure) is drawn by assigning limit stoichiometry according to the trivalent state of plutonium, to each composition of the limiting phase. The linear variation of the lattice parameter with the $\mathrm{PuO}_{2}$ content of the stoichiometric mixed oxide is plotted as line $b$. Since the lattice parameter vs $\mathrm{O} / \mathrm{M}$ plot for a mixed oxide of given plutonium concentration, say $\mathrm{U}_{1-c} \mathrm{Pu}_{c}$ oxide, is also a straight line (Dean and Pascard 1967; Blank et al 1967; Markin and Street 1967), the plot is simply obtained by joining with a straight line the limit compositions, $\mathrm{U}_{1-c} \mathrm{Pu}_{c} \mathrm{O}_{2-0.5 c}$ on plot a and $\mathrm{U}_{1-c} \mathrm{Pu}_{c} \mathrm{O}_{2.00}$ on plot $\mathrm{b}$. This way the lattice parameter vs $\mathrm{O} / \mathrm{M}$ plots for different plutonium concentrations of the mixed oxide are drawn. By knowing the lattice parameter of a mixed oxide of known plutonium concentration its $\mathrm{O} / \mathrm{M}$ can be obtained from a suitable plot in figure 2 .

\subsection{Two-phase mixed oxide}

The overall $\mathrm{O} / \mathrm{M}$ of a mixed oxide consisting of two phases can be obtained by taking the weighted mean of the individual $\mathrm{O} / \mathrm{Ms}$ of the two phases. If $m$ denotes the mole fraction of $\mathrm{MO}_{2-x}$ phase in a mixture of $\mathrm{MO}_{2.00}$ and $\mathrm{MO}_{2-x}$ phases, the overall $\mathrm{O} / \mathrm{M}$ of the mixed oxide will be given by

$$
\begin{aligned}
\mathrm{O} / \mathrm{M} & =(1-m) \times 2.00+m(2-x) \\
& =2.00-m x
\end{aligned}
$$

To find the $\mathrm{O} / \mathrm{M}$ of a two-phase mixed oxide, therefore, the values of $x$ and $m$ should be known. The deviation from stoichiometry of the $\mathrm{MO}_{2-x}$ phase is given, based on the trivalent state of plutonium, as

$$
x=0.5 C_{\mathrm{Pu}} /\left(C_{\mathrm{U}}+C_{\mathrm{Pu}}\right)
$$

where $C_{\mathrm{U}}$ and $C_{\mathrm{Pu}}$ are atomic concentrations of uranium and plutonium in the mixed oxide.

In the $\mathrm{MO}_{2-x}$ phase containing $76 \%$ plutonium, all the plutonium do not exist in the trivalent state as shown by Dean et al (1970). The departure from stoichiometry in this phase, therefore, is not given by (2). This phase has been shown to have an $\mathrm{O} / \mathrm{M}$ of 1.70 (Dean et al 1970), and so, an $x$ equal to 0.3. The value of $m$ can be obtained experimentally by measuring the $x$-ray line intensities of some selected reflections of the two phases as described below.

The ratio of the volumes of two phases, $\alpha$ and $\beta$ in a mixture is given in terms of the integrated intensities of their selected $x$-ray reflections, as

$$
V_{\alpha} / V_{\beta}=\frac{I_{\alpha}(h k l)}{I_{\beta}\left(h^{\prime} k^{\prime} l^{\prime}\right)} \frac{K_{\alpha}(h k l)}{K_{\beta}\left(h^{\prime} k^{\prime} l^{\prime}\right)}
$$

where $K(h k l)$ is a factor characteristic of the selected reflection $(h k l)$ and the crystal structure of the particular phase.

In mixed oxides having 35 to $50 \%$ plutonium, both $\mathrm{MO}_{2.00}$ and $\mathrm{MO}_{2-x}$ phases have a fluorite-type cubic structure. Their lattice parameter values are nearly the same. They differ in their oxygen contents, but this is not of much consequence in so far as the $K$ factors of the two phases are concerned since the atomic scattering factor of oxygen is much smaller than those of uranium and plutonium. Thus, for a given reflection $(h k l)$, the $K$ factor values for the two phases can be regarded as equal

$$
K_{\alpha}(h k l)=K_{\beta}(h k l) \text {. }
$$


In mixed oxides containing more than $50 \% \mathrm{Pu}$, the bcc structure of the $\mathrm{MO}_{2-x}$ phase is in fact identical in atomic arrangement to the fluorite structure of the $\mathrm{MO}_{2.00}$ phase, except that the vacancies in its oxygen sublattice are ordered, giving rise to a bcc super lattice (Gardner et al 1965). Thus, for the same reasons as advanced in the preceding paragraph, for a given reflection $(h k l)$, the $K$ factors for $\mathrm{MO}_{2 \cdot 00}$ and $\mathrm{MO}_{2-x}$ phases can be regarded as equal.

An x-ray diffraction pattern of hypostoichiometric mixed oxide containing $76 \%$ plutonium is shown in figure 3 . It is seen that the lines of the rhombohedral $\mathrm{MO}_{2-x}$ phase closely precede the corresponding lines of the cubic $\mathrm{MO}_{2.00}$ phase. Because of the low symmetry of the rhombohedral structure vis-a-vis the cubic structure, some of its lines are split into two. It has been shown (Dean et al 1970) that the rhombohedral structure of the $\mathrm{MO}_{2-x}$ phase is a slightly distorted form of the fluorite structure of the $\mathrm{MO}_{2} .00$ phase (rhombohedral: $a=5.5087 \AA$ and $\alpha=89.525^{\circ}$; cubic: $a=5 \cdot 4147 \AA, \alpha=90^{\circ}$ ). Therefore, the $K$ factors for equivalent reflections of $\mathrm{MO}_{2-x}$ and $\mathrm{MO}_{2.00}$ phases should be nearly equal. In the case of the split lines of the rhombohedral phase, the combined $K$ factor for the pair of split lines is equal to the $K$ factor for the corresponding single line of the cubic phase. The $\{200\}$ line of the rhombohedral phase is not split into two (figure 3). Therefore,

$$
K_{r}\{200\}=K_{c}\{200\} \text {. }
$$

where the subscripts $r$ and $c$ denote rhombohedral and cubic phases respectively.

Thus, for all compositions of the mixed oxide,

$$
K_{\mathrm{MO}_{2 \cdot 00}}(h k l)=K_{\mathrm{MO}_{2-x}}(h k l) \text {, }
$$

where $(h k l)$ can be any reflection for mixed oxides containing 35 to $50 \%$ plutonium

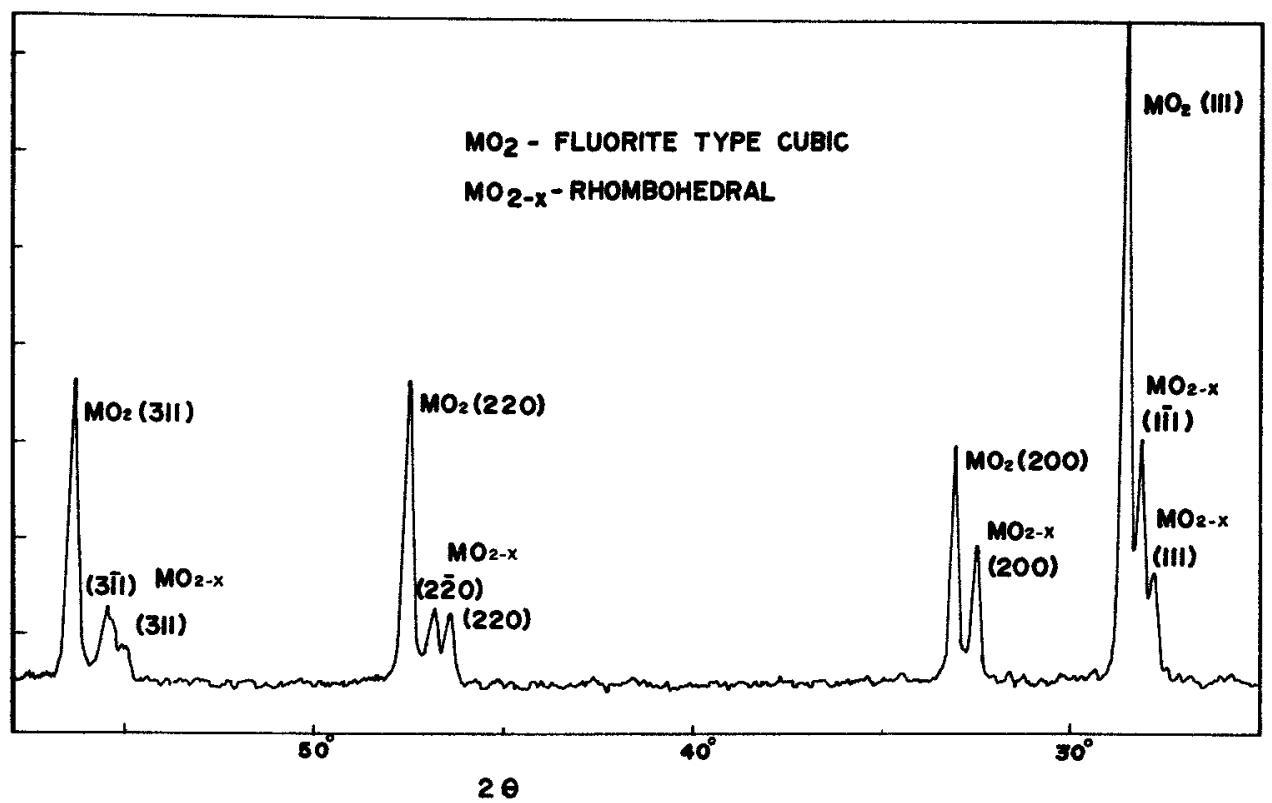

Figure 3. Rècorded trace of $(\mathrm{U} 0.24 \mathrm{Pu0} \cdot 76) \mathrm{O}_{2-x}$ diffraction pattern by $\mathrm{CuK}_{\alpha}$ radiation. 
and only the $\{200\}$ reflection in case of mixed oxide containing $76 \%$ plutonium. Using the above equality in (3), one gets

$$
V_{\alpha} / V_{\beta}=I_{\alpha}(h k l) / I_{\beta}(h k l) \text {. }
$$

The subscripts $\alpha$ and $\beta$ represent the $\mathrm{MO}_{2-x}$ and the $\mathrm{MO}_{2 \cdot 00}$ phases respectively. Since all the different crystal structures associated with $\mathbf{M O}_{2-x}$ phases are closely related to the flourite-type cubic structure of the $\mathrm{MO}_{2.00}$ phase, both these phases will have the same number of molecules per unit cell or per unit volume. Now, if $m_{\alpha}$ and $m_{\beta}$ represent the number of moles of $\mathrm{MO}_{2-x}$ and $\mathrm{MO}_{2.00}$ phases, respectively, in a given mixed oxide sample, then

$$
m_{\alpha} / m_{\beta}=V_{\alpha} / V_{\beta} \text {. }
$$

Substitution from (4) gives

or

$$
\begin{aligned}
& m_{\alpha} / m_{\beta}=I_{\alpha}(h k l) / I_{\beta}(h k l), \\
& m=m_{\alpha} /\left(m_{\alpha}+m_{\beta}\right)=I_{\alpha}(h k l) /\left[I_{\alpha}(h k l)+I_{\beta}(h k l)\right],
\end{aligned}
$$

where $m$ is mole fraction of the $\mathrm{MO}_{2-x}$ phase in the mixed oxide. Knowing the values of $x$ and $m$ from (2) and (5) respectively, the $\mathrm{O} / \mathrm{M}$ of unknown mixed oxide can be obtained from (1).

With the help of (1) $m$ vs $\mathrm{O} / \mathrm{M}$ plots for three different mixed oxide compositions $\mathrm{U}-35,50$ and $76 \% \mathrm{Pu}$, have been drawn in figure 4. The values of $\mathrm{O} / \mathrm{M}$ for unknown

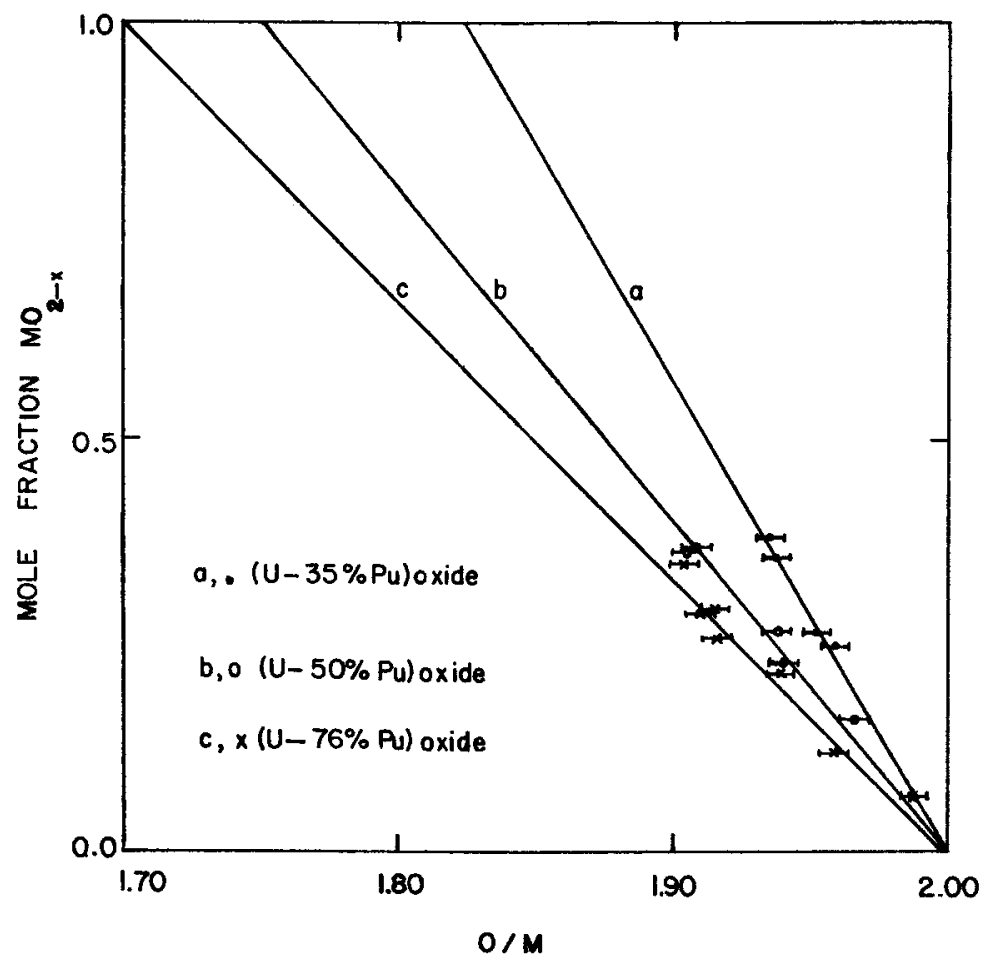

Figure 4. Amount of substoichiometric phase versus overall $\mathrm{O} / \mathrm{M}$ of the two-phase mixed oxide; theoretical plots $(-)$ and experimental data points (- - - ) 
mixed oxides belonging to these compositions can be read from these plots against their $m$ values obtained from (5).

\section{Experimental}

Mixed pellets of compositions $\mathrm{UO}_{2}-20,25,30,35,50$ and $76 \% \mathrm{PuO}_{2}$ were homogenized at $2073 \mathrm{~K}$ for $30 \mathrm{hr}$ in a dry (100 ppm moisture) $\mathrm{Ar}+8 \% \mathrm{H}_{2}$ atmosphere. The measurement of $\mathrm{O} / \mathrm{Ms}$ of representative pellets by the thermogravimetric method showed that all the mixed oxides were highly reduced. The process of $\mathrm{O} / \mathrm{M}$ measurement by the thermogravimetric method adjusts the $\mathrm{O} / \mathrm{M}$ of the mixed oxide pellet to $2 \cdot 00$. These $\mathrm{O} / \mathrm{M}$ adjusted pellets are free from oxygen inhomogeneity and other phases and are thus suitable for assessing the metal atom homogeneity in the mixed oxides by the x-ray diffraction technique. X-ray diffraction patterns of all the $\mathrm{O} / \mathrm{M}$ adjusted pellets showed sharp lines belonging to a single fcc phase. They also showed well-resolved $\left(K \alpha_{1}-K \alpha_{2}\right)$ doublets for the (531) reflection, confirming that all the mixed oxides were well homogenized.

As-homogenized (non adjusted) pellets were heated at $373 \mathrm{~K}$ in air. For each of the various mixed oxide compositions, one pellet was removed from the furnace after every $15 \mathrm{~min}$ of heating and stored in an inert atmosphere. This was continued till the last set of pellets was removed. Thus, pellets of different $\mathrm{O} / \mathrm{Ms}$ were obtained in all the mixed oxide compositions. Each of these pellets was broken into two halves; one half was used to determine $\mathrm{O} / \mathrm{M}$ by the thermogravimetric method and the other half was used to record the $\mathrm{x}$-ray diffraction pattern. For mixed oxides containing 20 , 25 and $30 \%$ plutonium (single-phase mixed oxides) precise lattice parameter values were determined by 'extrapolation' method using high angle lines. For mixed oxides containing 35 and $50 \%$ plutonium, the $\{311\}$ reflection and in the case of mixed oxide containing $76 \%$ plutonium, the $\{200\}$ reflection was recorded at a slow scanning speed of $1 / 8^{\circ}$ in $2 \theta / \mathrm{min}$. These reflections consisted of two peaks each, corresponding to the $\mathrm{MO}_{2 \cdot 00}$ and the $\mathrm{MO}_{2-x}$ phases. The integrated peak intensities $I_{\mathrm{MO}_{2 \cdot 00}}$ and $I_{\mathrm{MO}_{2-x}}$ were obtained by measuring areas under individual peak profiles. In mixed oxide containing $35 \%$ plutonium, however, the two peaks overlapped each other as shown in figure 5 and measuring the area under the individual peak was very difficult. This difficulty was overcome by correcting the peak profiles for the instrumental broadening by line profile analysis technique described elsewhere (Verma 1983). The measured integrated intensities were substituted in (5) to obtain mole fractions of the $\mathrm{MO}_{2-x}$ phase in mixed oxide samples of different compositions.

\section{Results and discussion}

The experimental data points based on measured lattice parameter and $\mathrm{O} / \mathrm{M}$ values of the single phase mixed oxides are plotted in figure 2 . It is seen that the data points are scattered not too closely on both sides of the theoretical lattice parameter vs $\mathrm{O} / \mathrm{M}$ plots. The $\mathrm{O} / \mathrm{M}$ values of various mixed oxide samples were also obtained against the respective measured lattice parameter values from these theoretical plots. The differences between the $\mathrm{O} / \mathrm{M}$ values thus obtained and the $\mathrm{O} / \mathrm{M}$ values measured by the thermogravimetric method are plotted against the latter in figure 6 .

In the case of two-phase mixed oxides, the experimental data points based on 


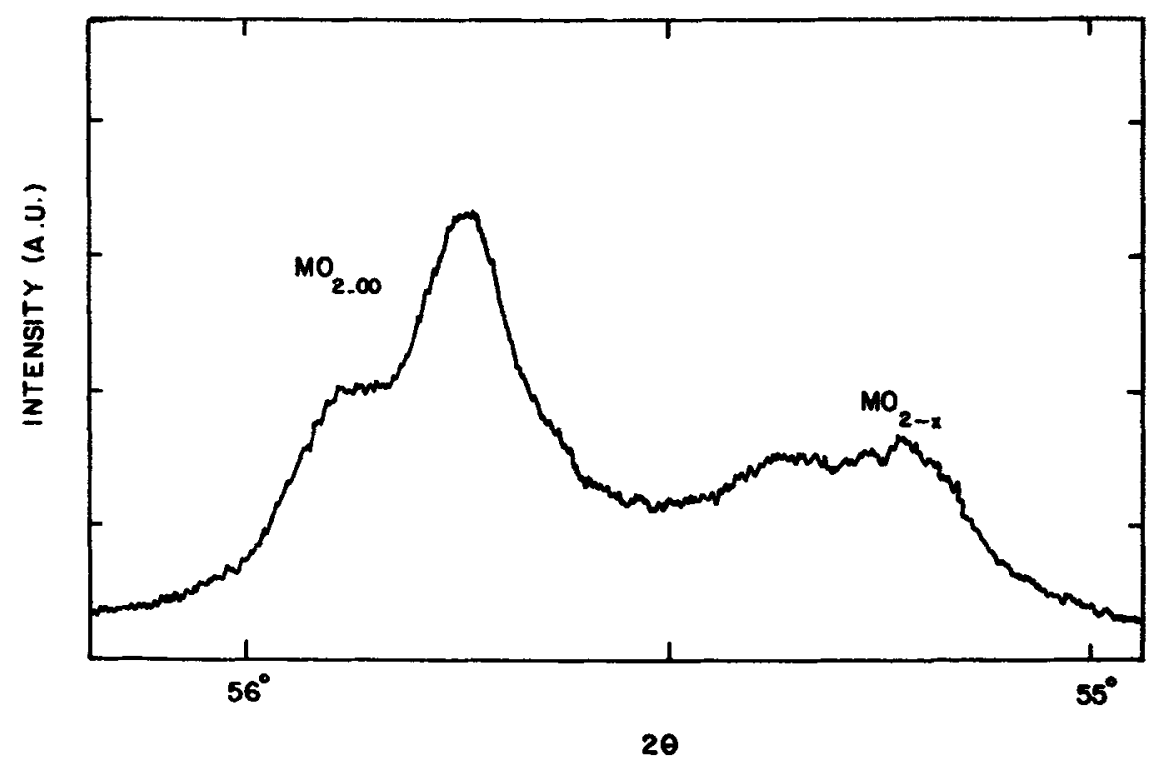

Figure 5. (311) Reflection profile recorded from $\left(\mathrm{UO}_{2}-35 \% \mathrm{PuO}_{2}\right)$ mixed compact sintered in a reducing atmosphere.

measured $\mathrm{MO}_{2-x}$ phase fractions and $\mathrm{O} / \mathrm{M}$ values obtained by thermogravimetric method are plotted in figure 4. The data points in this case fit the theoretical $\mathrm{MO}_{2-x}$ phase fraction versus $O / M$ plots fairly well. The differences in the $O / M$ values obtained from the theoretical plots and those measured by the thermogravimetric method are plotted against the latter in figure 6.

It could be seen that the differences between the calculated and the measured $O / M$ values are larger in the case of single phase mixed oxides than those of two-phase mixed oxides. The points in figures $6 \mathrm{a}$ and $6 \mathrm{~b}$ show standard deviations of \pm 0.01 and \pm 0.005 respectively, from the $\mathrm{O} / \mathrm{M}$ values measured by the thermogravimetric method. The thermogravimetric method of $\mathrm{O} / \mathrm{M}$ measurement being the reference method in this study, the $\mathrm{O} / \mathrm{M}$ values obtained by this method may be treated as absolute. The standard deviations of \pm 0.01 and \pm 0.005 , therefore, represent the accuracies of $\mathrm{O} / \mathrm{M}$ measurement by the $\mathrm{x}$-ray method in the context of single-phase and two-phase mixed oxides respectively. The accuracy of the $\mathrm{x}$-ray method in single-phase mixed oxides is thus rather poor whereas in two-phase mixed oxides the accuracy of this method is comparable to that reported for the thermogravimetric method.

An $\mathrm{O} / \mathrm{M}$ measurement by the $\mathrm{x}$-ray method takes less than an hour which is much shorter a period as compared to $6-8 \mathrm{hr}$ required by the thermogravimetric method.

\section{Conclusions}

The $\mathrm{x}$-ray diffraction technique provides a convenient method for measuring the $\mathrm{O} / \mathrm{M}$ of U-Pu mixed oxides. In single-phase mixed oxides $(\mathrm{Pu}<30 \%)$, the $\mathrm{x}$-ray method is based on measurement of the lattice parameter of the mixed oxide. The 

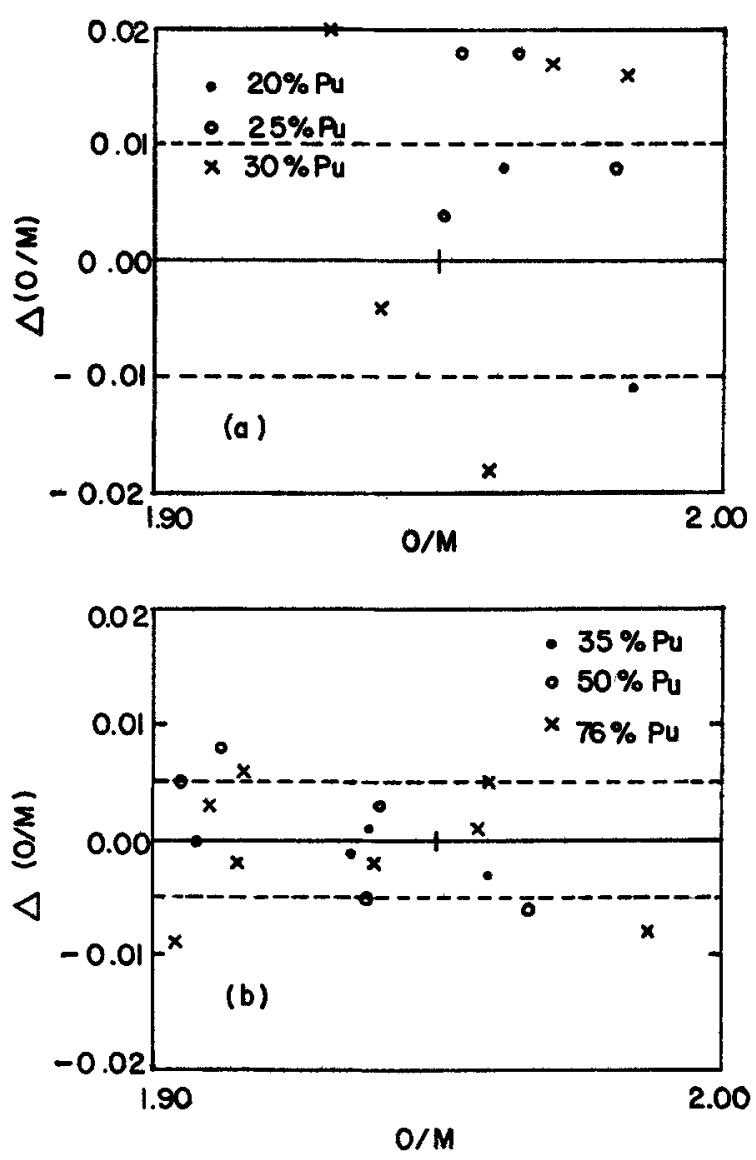

Figure 6. Difference in $\mathrm{O} / \mathrm{M}$ determined by $\mathrm{x}$-ray method and that determined by thermogravimetric method versus the latter; (a) single-phase mixed oxides, (b) two-phase mixed oxides.

accuracy of the method is approximately \pm 0.01 which is poor compared to that of the thermogravimetric method.

For two-phase mixed oxides, the $\mathrm{x}$-ray method of $\mathrm{O} / \mathrm{M}$ measurement is based on measuring the volume fractions of the stoichiometric and the sub-stoichiometric phases in the mixed oxide. In this case the x-ray method has an accuracy of \pm 0.005 , which is comparable to that reported for the thermogravimetric method.

As compared to the thermogravimetric method, the $\mathrm{x}$-ray method is faster, nondestructive and does not require a furnace or gas handling system. The method can be easily automated for on-line applications.

\section{References}

Belle J 1961 Uranium dioxide: Properties and nuclear applications Naval Reactors, Division of Reactor Development, USAEC

Blank H, Benedict U and Sari C 1967 in Technical Report Series (Vienna:IAEA) No. 79 p. 56

Brett N H and Russell L E 1963 Trans. J. Br. Ceram. Soc. 6297 
Dean G 1965 Proc. 3rd Int. Conf. on Plutonium (ed) A E Kay and M B Waldron (London: Chapman and Hall)

Dean G and Pascard R 1967 in Technical Report Series (Vienna:IAEA) No. 79 p. 56

Dean G et al 1970 Proc. 4th Int. Conf. on Plutonium and other actinides Santa Fe, New Mexico (ed) William N Miner (New York: Metallurgical Society)

Gardner E R, Markin T L and Street R S 1965 J. Inorg. Nucl. Chem. 27541

Gibby R L 1969 Battelle Northwest (USA) Report BNWL 927

Lay K W $1971 \mathrm{~J}$. Am. Ceram. Soc. 5418

Lyon W L 1963 General Electric (USA) Report GEAP 4271

Lyon W L and Bailey W E 1965 Trans. Am. Nucl. Soc. 8376

Markin T L and Street R S 1967 J. Inorg. Nucl. Chem. 292265

Matzke H J 1976 in Plutonium and other actinides (Amsterdam: North Holland) p. 801

McNeilly C E and Chikella T D 1971 J. Nucl. Mater. 3977

Mufford R N R and Ellinger F H 1958 J. Am. Ceram. Soc. 802023

Schmidt H E 1968 Progress Report 4, European Institute for Transuranium Elements

Van Craeynest J C and Weilbacher J C 1968 J. Nucl. Mater. 26132

Varma R 1983 J. Nucl. Mater. 118325

Zebroski E L, Lyon W L and Baily W E 1965 Int. Conf. on Safety, Fuels and Core Design in Large Fast Breeder Reactors, Argonne 